\title{
URUGUAI: OS MOVIMENTOS SOCIAIS DURANTE O GOVERNO DE JOSÉ MUJICA (2010-2015)*
}

\author{
URUGUAY: SOCIAL MOVEMENTS DURING \\ JOSE MUJICA'S GOVERNMENT (2010-2015)
}

\author{
Carlos Moreira e Tamara Lajtman ${ }^{b}$
}

\begin{abstract}
Resumo Durante os últimos cinco anos, o Uruguai experimentou sinais de revitalização da participação social, especialmente em setores juvenis. Em certos casos, isso pareceu transbordar os partidos políticos. Com efeito, uma multiplicidade de atores logrou mobilizar milhares de pessoas em torno de diversas demandas. Quando (e por que) surgiu essa heterogeneidade de mobilizações sociais? Como se organizaram para tão diversos objetivos? Que impacto tiveram suas ações sobre as múltiplas políticas públicas que abarcaram? Essas são perguntas que serão abordadas no artigo. Trata-se de uma análise conjuntural do passado recente, que se desenvolve em quatro partes: na primeira, abordam-se alguns aspectos teóricos da questão; na segunda, apresentam-se os antecedentes do tema e a hipótese principal; em seguida, analisam-se a emergência dos novos movimentos (quando), suas características organizativas (como) e o impacto sobre as políticas públicas (o quê); ao final, inclui-se uma seção conclusiva.
\end{abstract}

Palavras-chave Uruguai; governo de José Mujica; movimentos sociais; políticas públicas.

Abstract During the last five-year period, Uruguay showed signs of revitalization of its social participation, especially among youth sectors. In some cases this revitalization seemed to overwhelm political parties and multiple actors managed to mobilize thousands of people around several claims. When (and why) did this heterogeneity of social mobilization emerge? How did they organize themselves for such diverse objectives? What is the real impact their actions achieved over the multiple public policies that they encompassed? These are some of the questions we will cover in this paper. It is a analysis on the recent past, and is developed in four parts: at first, some theoretical aspects are covered; in the second, the background and our main

\footnotetext{
Artigo traduzido do original, Uruguay: los movimientos sociales durante el gobierno de José Mujica (2010-2015), por Bruna Nunes da Costa Triana, doutoranda em Antropologia Social pela Universidade de São Paulo (Ppgas-USP) e bolsista da Fundação de Amparo à Pesquisa do Estado de São Paulo (FAPESP).

a Professor da Universidade Autônoma de Baixa Califórnia, México.

b Mestra pelo Programa de Pós-Graduação em Estudos Latino-Americanos da Universidade Nacional Autônoma do México.
} 
intuition are presented; after, the emergence of new movements (when) is analyzed, as well its organizational characteristics (how), and the impact on public policies (what). Finally, a conclusion section is incorporated.

Keywords Uruguay; José Mujica’s government; social movements; public policy.

\section{INTRODUÇÃo}

Quando e por que surgiram, no Uruguai contemporâneo, fenômenos de mobilização social que, em alguns casos, parecem ter transbordado o Estado e, principalmente, os partidos políticos? Como se organizaram essas expressões de mobilização fundamentalmente juvenis? Que impacto tiveram sobre as políticas públicas durante o governo de José Mujica? O propósito deste artigo é analisar a atualidade da mobilização social no Uruguai, considerando uma série de organizações com forte presença no espaço público, durante os últimos cinco anos, em torno da meta de impulsionar a aprovação dos novos direitos (descriminalização do aborto, matrimônio igualitário e legalização da cannabis). A isso agregam-se a apreciação da assembleia que se opôs à exploração de uma mina de ferro e à construção de um porto de águas profundas, assim como da comissão que impulsionou as mobilizações de repúdio à redução da idade de imputabilidade penal.

O objetivo central aqui é identificar alguns dos elementos que estão presentes na origem, na trajetória e no impacto dessas organizações sobre o campo das políticas públicas. Além disso, pretende-se buscar indícios sobre as perspectivas de futuro das organizações consideradas e suas mobilizações.

A hipótese é que o Uruguai vive uma transição nas relações dos movimentos sociais com os partidos políticos e com o Estado. Por um lado, isso parece seguir as velhas rotas profundamente traçadas na história nacional; e, por outro, é possível encontrar sinais de que se começa a transitar por caminhos diferentes. Não se sabe se essa transição irá se consolidar ou ficará truncada. Em todo caso, isso poderia marcar a diferença entre a continuidade com o passado e o advento de uma nova época.

Este trabalho é uma análise do passado recente e se desenvolve em quatro partes: na primeira, abordam-se alguns aspectos teóricos; na segunda, apresentam-se os antecedentes do tema e a principal hipótese; na terceira, analisam-se a emergência dos novos movimentos (quando), suas características organizativas (como) e o impacto sobre as políticas públicas (o quê); ao final, expõem-se algumas conclusões. 


\section{ASPECTOS TEÓRICOS}

As mobilizações de que nos ocupamos neste trabalho foram dinamizadas por atores que cumprem com as definições mais aceitas, hoje, de movimentos sociais: estabilidade organizativa fraca; orientação conflitiva ao poder (Estado, instituições e/ou partidos políticos); linhas de ação que seguem, predominantemente, caminhos diferentes dos mais convencionais; comunidade de ideias, objetivos e interesses; e vontade de intervir nas políticas públicas (Marti i Puig, 2015).

Esses movimentos sociais estão fortemente condicionados pela estrutura de oportunidades políticas (EOP) da qual emergem (Rodríguez ArechavaleTA, 2010). Os estudos dos movimentos sociais permitiram identificar, por exemplo, uma série de fatores do meio ambiente que pode influir favoravelmente em sua emergência: em primeiro lugar, um Estado flexível, que permite o ingresso dos mobilizados às elites estatais; em segundo lugar, a articulação com aliados poderosos; e, em terceiro lugar, a sintonia com um momento favorável por que passa o mundo ou algumas regiões específicas (MArTi i PUig, 2015).

Sob essa perspectiva contextual, é possível abordar perguntas sobre quando surgem fenômenos de mobilização social, identificando as condições contextuais que a tornaram possível. Ademais, como sustentaram alguns autores, pode ser o próprio movimento social que cria as EOP que lhes são favoráveis, por meio de suas próprias ações (MARTi i PUig, 2015), concretizando um processo de mútuas influências e também condicionamentos, tal como se expressa na Figura 1.

Por outro lado, é necessário considerar as variáveis organizativas dos movimentos sociais. Aos estudos pioneiros de Charles Tilly somaram-se a teoria da mobilização de recursos, que sustenta que a capacidade de obter e mobilizar recursos tem efeitos-chave para a organização, e a teoria dos marcos cognitivos, que centra a atenção na produção de significados culturais (MARTi I PUIG, 2015).

Finalmente, devem-se examinar, também, as relações entre os movimentos sociais e as políticas públicas, de modo a medir o impacto dos primeiros sobre as segundas. Nessa perspectiva de análise de resultados, encontram-se trabalhos que abordam a questão do êxito ou fracasso dos movimentos no momento de concre-

Variável EOP
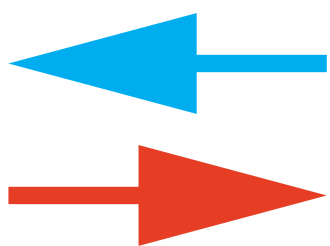

Variável movimento social

Figura 1. Influências mútuas entre EOP e movimento social. 
tizar os objetivos de transformação da ordem existente, assim como os desafios metodológicos que estão implicados no esforço de medir essas consequências (LÓPEZ LEYva, 2012).

Em seguida, considerando essa bibliografia, utilizaremos as três perspectivas (contextual, organizativa e de resultados) para um exame preliminar da emergência, da trajetória e dos impacto das mobilizações sociais no Uruguai, durante o período de governo de José Mujica (2010-2015).

\section{ANTECEDENTES DO TEMA}

Praticamente, desde o início do novo século, existe uma situação estendida no plano regional, na América Latina, de instalação de governos progressistas, que coincide com uma etapa de expansão dos chamados novos movimentos sociais, tanto de cunho classicista tradicional como de novíssimos movimentos. Nessa medida, as relações entre os movimentos sociais e os governos progressistas têm sido ambivalentes, ao oscilar entre o consenso e a confrontação. O eixo mais significativo dos debates se localizou em torno da questão do chamado neoextrativismo, pois, na medida em que os novos governos adotaram esse padrão de desenvolvimento, tiveram de enfrentar a oposição dos movimentos sociais ambientalistas.

Nesse contexto regional, em meados da primeira década do século XXI, o Uruguai apresentava uma situação particular: os movimentos sociais tradicionais, como o sindical e o estudantil, possuíam uma autonomia reduzida em relação ao sistema de partidos e, em consequência, apareciam como uma das poucas exceções no continente, pois, em contraste com o que ocorria em países como Bolívia, Equador, Venezuela ou Argentina, a disputa eleitoral e institucional dominava a disputa nas ruas. Assim, a chave para entender os movimentos sociais no Uruguai estava, até então, quase que exclusivamente na política, isto é, no Estado e nos partidos, ou, segundo as palavras de um especialista, na própria "domesticação e subordinação das lutas sociais aos interesses político-partidários” (ZiBECHI, 2000, p. 29).

A situação começou a mudar a partir do ano de 2005, com o triunfo da Frente Ampla e seu acesso ao poder. A partir desse momento, ficou evidente que se começava a produzir um distanciamento entre o Estado, a coalizão de esquerda e uma parte dos movimentos sociais tradicionais, com a ruptura entre situação e oposição, entre moderados e radicais, entre os que aceitavam o gradualismo das políticas do governo de Tabaré Vázquez e os que reclamavam por reformas mais drásticas e estruturais. 
Sem dúvida, o papel do Estado e dos partidos políticos sobre os movimentos sociais continuou sendo importante, condicionando boa parte de suas possibilidades de emergência e desenvolvimento; todavia, ao mesmo tempo, abriu-se uma janela de oportunidades para o desenvolvimento de movimentos sociais autônomos. É nesse sentido que começaram a se mesclar elementos tradicionais com novidades. Emergiram alguns movimentos e se reativaram outros, que tinham apenas existência formal, a fim de demandar ao governo de Tabaré Vázquez a aprovação de novos direitos: descriminalização do aborto, matrimônio igualitário e legalização da cannabis.

Isso, ademais, foi acompanhado de uma latino-americanização da política uruguaia, no momento em que começou a se propagar, durante o primeiro governo da Frente Ampla, certo desencanto com os partidos, especialmente com a Frente, mais visível entre os setores mais radicais e jovens. Como exemplos é possível citar a ruptura de um grupo da Frente Ampla com a coalizão de esquerda, em 2006, formando um novo partido político (Assembleia Popular), ou o acentuado aumento dos votos em branco e dos votos nulos nas eleições municipais de 2010.

Nesse contexto, que combinava elementos tradicionais e novos na relação da sociedade mobilizada com seus representantes políticos e estatais, José Mujica assumiu a presidência em 2010, de modo a produzir um giro à esquerda nas políticas públicas. Como mostra o Quadro 1, durante seu governo, produziram-se avanços consideráveis em relação a direitos sociais, o que levou o Uruguai a ser considerado o país mais liberal da América Latina, pelo centro de estudos estadu-

Quadro 1. Uruguai e os novos direitos (2010-2015).

\begin{tabular}{|c|c|c|c|c|}
\hline Novos direitos & $\begin{array}{c}\text { Organizações } \\
\text { vinculadas }\end{array}$ & Lei & Iniciativa & $\begin{array}{c}\text { Data de } \\
\text { aprovação } \\
\text { parlamentar }\end{array}$ \\
\hline Aborto & $\begin{array}{l}\text { Mujer y Salud } \\
\text { Uruguay (MYSU) }\end{array}$ & $\begin{array}{l}\mathrm{n}^{\circ} 18.987 \\
\text { Interrupção } \\
\text { voluntária da } \\
\text { gravidez }\end{array}$ & $\begin{array}{l}\text { Poder } \\
\text { Legislativo }\end{array}$ & $17-10-2012$ \\
\hline $\begin{array}{l}\text { Matrimônio } \\
\text { igualitário }\end{array}$ & Ovejas Negras & $\begin{array}{l}\mathrm{n}^{\circ} 19.075 \\
\text { Matrimônio } \\
\text { igualitário }\end{array}$ & $\begin{array}{l}\text { Poder } \\
\text { Legislativo }\end{array}$ & $10-04-2013$ \\
\hline Cannabis & $\begin{array}{l}\text { Movimiento por } \\
\text { la Legalización del } \\
\text { Cannabis (Laplacita, } \\
\text { Plantatuplanta, } \\
\text { Prolegal) }\end{array}$ & $\begin{array}{l}\mathrm{n}^{\circ} 19.172 \\
\text { Cannabis e seus } \\
\text { derivados }\end{array}$ & $\begin{array}{l}\text { Poder } \\
\text { Executivo }\end{array}$ & $10-12-2013$ \\
\hline
\end{tabular}

Fonte: Elaboração própria com base nos dados disponíveis em:< www.parlamento.gub.uy>. 
nidense Pew Research Center, e “o país do ano de 2013”, pelo influente periódico britânico The Economist.

Entre os anos 2010 e 2015, as organizações vinculadas à aprovação desses direitos impulsionaram mobilizações sociais com participação massiva, especialmente de jovens, e pode-se perceber como o êxito acompanhou essas mobilizações, que materializaram seus objetivos. Em outras palavras, entre 2010 e 2015, parece ter ocorrido uma combinação entre um contexto de oportunidades políticas favoráveis e as ações dos próprios movimentos em produzir resultados exitosos em termos de políticas públicas.

Simultaneamente, em 2011, surgiu o Movimiento por un Uruguay Sustentable, que convocou mobilizações massivas para oposição a um projeto mineiro-portuário do governo. Ainda nesse mesmo ano, a recém-criada Comisión de No a la Baja ${ }^{1}$ fez o mesmo, opondo-se às pretensões de um setor do Partido Colorado de reduzir a idade de imputabilidade penal de dezoito para dezesseis anos. No conjunto, todos esses movimentos outorgaram ao período de governo de José Mujica uma grande efervescência social. A seguir, será possível vislumbrar mais detalhes desses processos.

\section{PERSPECTIVAS DE ANÁLISE}

\section{CONTEXTUAL}

O Uruguai foi um dos poucos países, junto com a URSS, que legalizaram o aborto na primeira metade do século XX. Uma reforma no Código Penal, impulsionada por José Irureta Goyena, em 1933, tornou possível que se praticasse a interrupção da gravidez nos hospitais públicos do país. Poucos anos depois, em 1938, o aborto foi novamente tipificado como crime pela Lei $\mathrm{n}^{0} 9.763$, que penalizava tanto a mulher como o médico responsável. Passados os anos da ditadura civil-militar, a redemocratização, iniciada em 1985, abriu espaços para debates públicos acerca da saúde da mulher; debates que começaram a fazer parte das consecutivas agendas de governo, resultando na apresentação de seis Projetos de Lei, em esfera parlamentar, entre 1985 e 2007.

A partir do início do século XXI, a descriminalização do aborto passou de uma demanda quase exclusiva das organizações feministas a uma demanda sustentada por diferentes atores da sociedade civil nacional. "Isto foi produto do

1 NT: Comissão Contra a Redução da Maioridade Penal. 
próprio acionar das organizações feministas que mantiveram uma estratégia de ampliação de alianças e de base social a favor da mudança legal e dos direitos das mulheres" (Johnson; Gómez; Schenck, 2011, p. 250).

Em 2008, ambas as câmaras aprovaram o Projeto de Lei que previa a eliminação das penas pela realização do aborto, mas os artigos principais foram vetados pelo Presidente Tabaré Vazquez, ficando instaurados o assessoramento pré-aborto e pós-aborto, assim como os capítulos referentes à educação sexual (Gioscia; Carneiro, 2013).

Foi nesse contexto que a mão laranja², com o lema "Voto a favor da Saúde Reprodutiva”, foi adotada como símbolo da participação cidadã; até a conjuntura da mudança normativa, ocorrida em 2012, acompanhou a ação das organizações sociais, entre elas o Movimiento Mujer y Salud, surgido em 1996.

A Lei $\mathrm{n}^{\mathrm{o}}$ 18.987, de Interrupção Voluntária da Gravidez, foi sancionada em 17 de outubro de 2012 e promulgada no dia 22 do mesmo mês, pelo então Presidente José Mujica. Setores da oposição empreenderam um processo de coleta de assinaturas para promover um referendo que permitisse anular a lei, o que não prosperou, pois contou com o respaldo de apenas $8,8 \%$ do eleitorado (sendo que era necessário um mínimo de 25\% para habilitar esse recurso).

Por sua vez, mesmo reconhecendo o avanço alcançado quanto às conquistas dos direitos sexuais e reprodutivos, a maioria das feministas não estava de acordo com o texto aprovado, que foi progressivamente modificado no curso das negociações parlamentares (Gioscia; CARnEIRo, 2013).

O Projeto de Lei $\mathrm{n}^{0}$ 19.075, do Matrimônio Igualitário, apresentado em abril de 2011 pelo deputado Sebastián Sabini, do Movimiento de Participación Popular, surgiu de um texto redigido pelo coletivo Ovejas Negras (criado em dezembro de 2004). O projeto foi respaldado por José Mijica e por dirigentes da oposição, como o ex-presidente colorado Julio María Sanguinetti. A lei habilitou a união civil independentemente de identidade, gênero ou orientação sexual.

Em relação a essa mudança normativa, aprovada pelo Parlamento em 10 de abril de 2013, é fundamental considerar a centralidade do coletivo Ovejas Negras e sua capacidade de incidência na agenda parlamentar. Diego Sempol (2014, p. 146), politólogo e integrante do coletivo, afirmou que a

2 NT: Em 2011, a ONG feminista Mrsu, Mujer y Salud en Uruguay, lançou uma campanha para alterar a legislação do país e tornar o aborto prática legal. A campanha Aborto Legal - Uruguay. Son tus derechos, hacelos valer! promoveu uma reflexão sobre a agenda dos direitos sexuais e reprodutivos e suas consequências. O logotipo mostrava uma mão laranja segurando uma flor. Consultar: <http://www.hacelosvaler.org/>. Acesso em: 29/05/2015. 
[...] chegada da FA [Frente Ampla] ao governo consolidou um novo marco de oportunidades para a ação política do movimento LGBTQ, o que contribuiu significativamente para sua capacidade de mobilização social. Por um lado, existiu um alto grau de abertura do sistema político e um incremento significativo da capacidade de incidência dos movimentos LGBQT, assim como a presença de aliados entre as elites para levar adiante uma agenda centrada no reconhecimento de direitos desses grupos tradicionalmente excluídos.

Em terceiro lugar, dentro de um contexto regional de forte repressão às drogas, algo acentuado ainda mais durante o último terço do século XX, o Uruguai sempre manteve um caráter distintivo em relação aos outros países na adoção flexível e moderada da legislação internacional. Inclusive, no começo dos anos 1980, instalou-se, especialmente entre os juristas, a discussão sobre a possibilidade de legalizar o consumo de drogas, a partir do autocultivo de cannabis.

Em 1998, aprovou-se a Lei ${ }^{0}$ 17.016, que significou um princípio de descriminalização do consumo; no início do século XXI, o governo de Jorge Battle propôs avançar em direção a uma legalização das drogas. A iniciativa foi retomada por setores juvenis da Frente Ampla e de demais associações da sociedade civil, agrupadas em torno do Movimiento por la Liberación del Cannabis (GARAT, 2013).

Em 2006, formou-se o Prolegal, e, ainda que Tabaré Vázquez fosse favorável a discutir o tema, foi apenas em junho de 2012 que o governo de Mujica fez os primeiro anúncios concretos que culminariam na descriminalização da cannabis, um ano e meio depois, em dezembro de 2013.

Em quarto lugar, ocorreram duas mobilizações sociais de caráter reativo, que é importante considerar aqui. No ano de 2011, Bordaberry e o Partido Nacional lançaram a campanha para reduzir a idade de imputabilidade penal de dezoito para dezesseis anos. Essa iniciativa foi levada a plebiscito no sentido de reformar a Constituição. Em oposição a ela, forma-se a Comisión de No a la Baja, que, embora tivesse apoio pela Frente Ampla e do Estado uruguaio, com o Instituto Nacional de la Juventud, logrou mobilizar milhares de jovens não integrados à Frente Ampla, inclusive aqueles mais descontentes com a própria Frente e com os sindicatos tradicionais ligados à situação, que conseguiram impedir que triunfasse a opção da redução.

Finalmente, a segunda mobilização social reativa de importância no Uruguai recente se produziu a partir da formação do Movimiento por un Uruguay Sustentable (Movus), cujos antecedentes se encontram na Asamblea Ambientalista, formada em 2007. O Movus surgiu para se opor, principalmente, à exploração pela 
empresa espanhola Aratirí de uma mina de ferro e a consequente construção de um porto de águas profundas. Ainda que, finalmente, o governo tivesse decidido deter os chamados megaprojetos, em razão da queda do preço internacional do ferro, o movimento realizou uma série de marchas multitudinárias.

Em balanço preliminar, pode-se dizer que o contexto no qual surgiram, em seu conjunto, essas mobilizações sociais apresenta características complexas, em que se misturam elementos tradicionais e elementos mais novos, no que se refere à relação do Estado e dos partidos políticos com os movimentos populares.

Por um lado, dentro dos elementos tradicionais de dependência do social em relação ao político, as mobilizações em torno dos novos direitos (descriminalização do aborto, matrimônio igualitário e legalização da cannabis) não enfrentavam o Estado ou o sistema de partidos, haja vista que o adversário era o que eles definiam como o núcleo conservador da sociedade. Por outro lado, surgem como uma novidade as margens de autonomia em relação aos partidos maiores que as mobilizações tiveram, especialmente quando se compara com o passado, pois eles se articularam com a face amigável por meio da qual se apresentou o Estado durante o governo de José Mujica. Nesse sentido, se se toma como referência a aprovação dos novos direitos nesses anos, é possível observar a produção de um círculo virtuoso entre novos movimentos sociais e Estado. Em outras palavras, a descriminalização do aborto, o matrimônio igualitário e a legalização da cannabis tiveram um impulso importante nas mobilizações sociais e só se tornaram possíveis na conjuntura do governo progressista.

Como declara a senadora da Frente Ampla Constanza Moreira, "os projetos de ampliação de direitos que foram votados na última década deste país têm exatamente esta origem: procedem da sociedade civil, são apropriadas pelas bancadas parlamentares e, assim, terminam modificando um estado de coisas"3. Talvez isso explique por que o desencanto de uma parte do eleitorado juvenil da esquerda com o governo de Tabaré Vázquez foi se atenuando nos fins do governo José Mujica.

Os atores sociais apresentaram uma visão mais crítica do sistema de partidos nos casos da Comisión de No a la Baja e do Movus. No primeiro, conviveram aqueles que se sentiam mais próximos da Frente Ampla com aqueles que viam o movimento como uma nova política para além dos partidos (Gutiérrez, 2014). No segundo, não houve tais matizes, e os atores sociais se autodefiniram como anticapitalistas e inimigos das multinacionais e seus aliados internos, isto é, o sistema de partidos (incluindo a Frente Ampla) e o próprio Estado. Em ambos

3 Disponível em: <proderechos.org.uy>. Declaração de 16/04/2013. Acesso em: 17/04/2015. 
os casos, de certa maneira, transbordaram o Estado e os partidos políticos, de maneira a desenvolver novas formas de autonomia em relação ao Estado e aos partidos, no primeiro caso - paradoxalmente, apoiando-se neles -, e, no segundo, rechaçando-os.

\section{ORGANIZATIVA}

Segundo a Teoria da Mobilização de Recursos, a sobrevivência dos novos movimentos sociais depende dos recursos, da organização e das ações desencadeadas. Segundo a Teoria dos Novos Movimentos Sociais, trata-se de organizações com objetivos de mudança que apresentam traços que as distinguem dos movimentos sociais tradicionais (AGUIAR, 2012).

Dessa maneira, é possível ordenar as novidades que as mobilizações sociais introduzem no panorama tradicional dos movimentos sociais no Uruguai, como se pode ver no Quadro 2 abaixo.

As organizações Mysu, Proderechos, Prolegal, Comisión No a la Baja e Movus lograram incorporar milhares de pessoas às mobilizações sociais que realizaram. A seguir, são apresentadas as características à luz das variáveis propostas no quadro.

\section{a) Ações}

Atuar é a chave das organizações para sua sobrevivência e seu êxito. Que tipos de ações realizavam esses movimentos sociais?

As formas de ação das mobilizações recentes no Uruguai incluíram formas não convencionais e convencionais. Entre as primeiras, encontram-se espetáculos

Quadro 2. Movimentos sociais tradicionais e novos.

\begin{tabular}{|c|c|c|}
\hline & Mobilização social tradicional & Novas mobilizações sociais \\
\hline Ações & Convencionais & $\begin{array}{l}\text { Convencionais e não } \\
\text { convencionais }\end{array}$ \\
\hline Objetivos e recursos & Gerais e políticos & Específicos e culturais \\
\hline Identidade e ideologia & Formada e definida & Em formação e difusa \\
\hline Organização interna & $\begin{array}{l}\text { Vertical e lideranças } \\
\text { definidas }\end{array}$ & $\begin{array}{l}\text { Horizontal e com múltiplos } \\
\text { referentes }\end{array}$ \\
\hline Setores sociais mobilizados & $\begin{array}{l}\text { Homogêneos classicistas, } \\
\text { hegemonia do setor } \\
\text { trabalhador }\end{array}$ & $\begin{array}{l}\text { Heterogêneos geracionais, } \\
\text { hegemonia da classe média } \\
\text { urbana }\end{array}$ \\
\hline $\begin{array}{l}\text { Relação prioritária com } \\
\text { outros atores }\end{array}$ & Formal & Informal \\
\hline
\end{tabular}

Fonte: Elaboração própria com base em Aguiar (2012). 
musicais, bicicletaços, piqueniques e uso intensivo da internet; entre as segundas, a utilização dos mecanismos eleitorais e a participação em comissões oficiais. Assim, ainda que haja uma desconfiança maior do que no passado, não há um rechaço total à política.

Um exemplo é o surgimento das Redes Frenteamplistas. A primeira atividade com impacto que realizaram foi uma convocatória, por ocasião das internas da Frente Ampla,

[...] mas o grande salto teve lugar em setembro de 2009: através do Facebook, um grupo de jovens chamou um "ramblazo"4. A Frente Ampla explicitou que não apoiava a iniciativa, as Redes sim, e compareceram milhares de pessoas. Depois disso, teve lugar a convocatória, pelas Redes, de uma série de "banderazos”, manifestações com uma bandeira confeccionada com retalhos trazidos por militantes com as cores da Frente Ampla. Desde então, eles mantêm presença pública, mais claramente em relação à estrutura do partido (AGUIAR, 2012, p. 44).

Desse modo, os novos movimentos sociais utilizam caminhos tradicionais de apego aos partidos políticos, ao mesmo tempo em que exploram vias mais autônomas. E, por isso, são os jovens mais politizados e com maior confiança nos canais partidários que impulsionam as mobilizações em relação aos novos direitos (cf. Aguiar, 2012).

\section{b) Objetivos e recursos}

Aqui, encontra-se uma diferença entre os movimentos sociais tradicionais, que se movem com objetivos gerais de transformação estrutural e mobilizam, para tanto, recursos políticos, e as novas mobilizações, que se guiam por objetivos mais específicos e mobilizam importantes recursos simbólicos.

Enquanto os movimentos sociais tradicionais falam da revolução e do socialismo - e se concentram na defesa dos direitos clássicos do estado de bem-estar social como algo prioritário (emprego, saúde, educação e moradia) -, as novas mobilizações tomam implicitamente esses direitos como algo de certa forma garantido, planejando mudanças das formas de viver, impulsionando, por exemplo, questões relativas a direitos humanos e ambientais.

4 NT: "Ramblazo" é como ficaram denominadas as caminhadas em protestos no Uruguai. Para exemplos da convocação e do que representou um desses "ramblazos", consultar: <http://movimientos.desdeadentro.co/ramblazo-el-inicio-callejero/>. Acesso em 29/05/2015. 
De fato, um desafio se coloca às organizações por terem objetivos tão específicos: uma vez que alcançam esses objetivos, elas devem se fixar nos objetivos seguintes, a partir de uma dinâmica mais cotidiana, o que conduz a interrogar sobre as possibilidades de permanência no tempo que esses movimentos podem ter.

\section{c) Identidade e ideologia}

A identidade é uma das questões centrais nos estudos dos novos movimentos sociais. No caso uruguaio, as organizações sociais consideradas foram conformando uma identidade, um nós, por intermédio de suas ações. Enquanto nas organizações de tipo tradicional a identidade está definida já há muito tempo, naquelas de novo tipo ela é mais indeterminada. E isso tem a ver, também, com uma relação que mantêm com o marco ideológico que, ainda que seja de esquerda, em ambos os casos, nos novos movimentos sociais aparece como menos definidora e mais pragmática que nos movimentos tradicionais.

\section{d) Organização interna}

Enquanto nos movimentos sociais tradicionais a organização interna é vertical e com lideranças definidas e fortes, nos novos movimentos as relações entre dirigentes e membros são horizontais, isto é, sem lideranças definidas, sendo que as decisões se tomam, em muitos casos, por consenso.

Um dos dilemas que se colocam a essas organizações é como se institucionalizar e não se converter em uma Organização Não Governamental (ONG), que é um desafio geral dos novos movimentos sociais, em muitas partes do mundo (MACHADO, 2004).

\section{e) Setores sociais mobilizados}

Os movimentos sociais tradicionais mobilizam homogeneamente os setores sociais, a partir da reivindicação de identidades de classe, geralmente sob a direção da classe trabalhadora. Os novos fenômenos de mobilização social, por sua vez, buscam um recrutamento social mais heterogêneo, com base em critérios geracionais (jovens versus adultos), nos quais é possível distinguir a hegemonia dos setores de classe média urbana.

f) Relação prioritária com outros autores 
Enquanto os movimentos sociais tradicionais já contam com uma extensa rede de alianças formais, os novos movimentos vão gestando essas alianças na prática cotidiana. Nesse sentido, no caso analisado, as organizações buscaram alianças com outras organizações que compartilham o mesmo campo de ação, apoiando-se mutuamente, tanto no sentido simbólico como no material. O que os une é o adversário comum, identificado como o setor conservador da sociedade uruguaia.

A relação com outros atores também tem um ponto de inflexão em como esses novos movimentos são visibilizados pela opinião pública. Ao longo do período de governo de José Mujica, a situação dos movimentos para a opinião pública foi cambiante: no começo, com hostilidade, a opinião pública se opunha majoritariamente à aprovação dos objetivos impulsionados pelos novos movimentos, até no final, exceto pela questão da legalização da cannabis, a maioria apoiava suas ações e a aprovação de novos direitos.

$\mathrm{O}$ fato de que essas mobilizações sociais foram se integrando à dinâmica política estatal certamente contribuiu para o processo de sua legitimação, assim como elas, ao mesmo tempo, contribuíram para a legitimação dos partidos e do próprio Estado democrático.

\section{RESULTADOS}

Avaliar o impacto que os atores sociais têm sobre as políticas públicas é um dos assuntos mais complexos de se trabalhar e, por sua vez, mais descuidados pela literatura acadêmica, que tende a trabalhar os movimentos sociais e as políticas públicas como mundos paralelos (LÓPEz LEYvA, 2012).

No caso do Uruguai, é interessante vincular ambos os temas e averiguar como os movimentos sociais interviram no processo de consolidação de políticas públicas, seja favorecendo, seja colocando obstáculos às mudanças.

Contudo, do ponto de vista metodológico, a medição de tal impacto não deveria ficar limitada à percepção dos movimentos ou políticos e funcionários estatais participantes, pois tais avaliações são subjetivas e tendem a sobrevalorizar o peso dos movimentos nos processos (LÓPEz LEYvA, 2012). Portanto, é necessário trabalhar essas questões tentando definir indicadores objetivos.

Nessa medida, uma proposta para uma investigação que aborde os impactos ou resultados das mobilizações sociais sobre as políticas públicas torna-se possível a partir da consideração de tal impacto em cada etapa do ciclo das políticas públicas, a saber: 1) ingresso na agenda governamental; 2) formulação da resposta; 3) tomada de decisões; 4) implementação; e 5) avaliação. 
Tal como assinala López Leyva (2012), os movimentos sociais tendem a ter um papel mais ou menos notável na transformação de um assunto social em um problema de agenda governamental ou pública. No caso uruguaio, isso parece mais claro nas mobilizações em relação ao matrimônio igualitário. Por sua vez, a descriminalização do aborto e a legalização da cannabis, como se sabe, estavam na agenda social desde os anos 1930 e 1980 e na agenda pública desde os anos 1980 e começo do novo século, respectivamente. Ou seja, aqui o papel das organizações e das mobilizações sociais parece ter sido menos influente nessa etapa do ciclo, uma vez que, de certa maneira, o Estado funcionou se antecipando à demanda.

No caso do movimento contrário à redução da maioridade penal, o assunto ingressou praticamente em uníssono na agenda social e na agenda política, ao ser tomado, simultaneamente, pelos partidos políticos, pela organização social e pelo governo da Frente Ampla.

Na etapa de formulação da resposta, no ciclo das políticas públicas, participaram ativamente as organizações vinculadas à descriminalização do aborto, ao matrimônio igualitário e à legalização da cannabis, já que foram aceitas nas comissões que redigiram os projetos de lei como interlocutores válidos. Por sua vez, o Movimiento de No a la Baja parece ter se movido de maneira mais autônoma em relação ao governo, desenvolvendo suas próprias ações e estratégias no sentido de formular, racionalmente, uma proposta alternativa. Uma investigação sobre as recentes etapas de tomada de decisões, implementação e avaliação ainda está pendente.

Seguindo a proposta de López Leyva (2012), poderíamos finalmente construir um índice de "êxito total" dos movimentos, a partir da somatória dos "êxitos parciais" em cada fase do ciclo da política, medidos pela participação nessas fases, conforme o Quadro 3.

Essa tarefa de avaliação de resultados e impactos é possível de ser realizada para os movimentos mencionados porque eles tiveram um papel proativo em

Quadro 3. Proposta para medir o impacto da mobilização social nas políticas públicas, considerando a participação nas etapas do ciclo político.

\begin{tabular}{|c|c|c|c|c|}
\hline & Aborto & Matrimônio igualitário & Cannabis & Não à redução \\
\hline $\begin{array}{l}\text { Ingresso na agenda } \\
\text { governamental }\end{array}$ & - & + & - & $+/-$ \\
\hline $\begin{array}{l}\text { Formulação da } \\
\text { resposta }\end{array}$ & + & + & + & - \\
\hline Tomada de decisões & ? & ? & ? & ? \\
\hline Implementação & $?$ & $?$ & $?$ & $?$ \\
\hline Avaliação & ? & ? & ? & ? \\
\hline Balanço & $+/-$ & + & $+/-$ & - \\
\hline
\end{tabular}

Fonte: Formulação própria com base em López Leyva (2012). 
relação às políticas públicas. No caso do movimento ambientalista, é interessante notar que ele seguiu uma rota reativa ou de oposição às iniciativas governamentais, e, portanto, seu papel nas etapas do ciclo deve ser considerado de maneira especial.

\section{CONCLUSÕES}

Neste trabalho, colocou-se à prova a hipótese de que o Uruguai vive uma transição na relação da mobilização social com os partidos políticos e o Estado, e os últimos cinco anos parecem ir confirmando, de certa maneira, essa tendência; isto é, por um lado, as mobilizações do período seguiram rotas tradicionais, enquanto, por outro, foram transitando por novos caminhos.

Quando começou a ser gestado esse processo? Na perspectiva aqui defendida, no momento em que a Frente Ampla assumiu o governo, em 2005, chegou ao fim a inter-relação estreita entre a coalizão de esquerda e o conjunto do movimento social. Dessa maneira, tornou-se possível o surgimento de organizações sociais que construíram ações com maiores margens de autonomia no que tange ao Estado e ao sistema de partidos.

A suspeita é de que, nesse momento, começou uma época híbrida, em que se misturaram alinhamentos tradicionais, Movimento-Partido-Estado, com organizações que se mobilizaram de maneira mais autônoma, buscando novos caminhos. Nessa medida, começou a ser gerado um espaço de mobilização social mais plural. Contudo, por que razão surgiram essas mobilizações sociais mais autônomas em relação aos partidos e às instituições do Estado?

Uma primeira razão pode ser encontrada no cumprimento de um ciclo, no qual a aliança entre o partido de esquerda e os movimentos populares, que se teceu nos anos 1980 e começo dos 1990, cumpriu com o objetivo que se havia proposto - que a esquerda chegasse ao poder. Portanto, abriu-se a possibilidade de tentar um novo relacionamento.

Um segundo fator que vale a pena considerar é o lento processo de renovação geracional nos movimentos sociais tradicionais, algo que parece ter encorajado os jovens a buscarem outros canais de participação social, tal qual sugerido por Sebastián Aguiar (2012), em seu interessante trabalho.

Finalmente, um terceiro fator, cujo peso deveria ser determinado mais especificamente, pode estar em certo desencanto das pessoas em relação aos partidos políticos, especialmente dos setores mais jovens com a Frente Ampla. Talvez isso não seja suficiente para falar da crise de representação dos partidos, tal qual em outros países latino-americanos; porém é evidente que, em alguns casos, as mobi- 
lizações capturaram um sentimento dos jovens de não se sentirem representados pelo partido de esquerda. Ainda é cedo para compreender isso, e os sinais são um pouco fracos para saber se se está diante de um anúncio do advento de outro tempo ou se se trata de um processo de transição que está prestes a permanecer incompleto (o que seria, em definitivo, uma falsa transição).

A pequena janela de oportunidades para mobilizações autônomas, que se abriu no período de 2005 a 2010, não se fechou, mas não se sabe, qualitativamente, até que ponto ela se ampliou. Esse é o dilema que se apresenta às perspectivas de futuro das organizações sociais e suas mobilizações populares: uma rearticulação estreita com o partido e o governo no bloco progressista, e, inclusive, nesse processo, sua integração nos movimentos sociais tradicionais - sindicais e estudantis -; ou o transitar por novos caminhos, até se converterem em movimentos sociais mais autônomos em relação às forças políticas e ao Estado.

\section{REFERÊNCIAS BIBLIOGRÁFICAS}

Aguiar, Sebastián. "Los movimientos sociales juveniles en Uruguay: situación en las últimas décadas y escenarios prospectivos”. Recso, Revista de Ciencias Sociales, v. 3, p. 38-66, 2012.

Garat, Guillermo. “Un siglo de políticas de drogas en Uruguay”. Análisis, n1, pp. 1-21, 2013. Gioscia, Laura; Carneiro, Fabricio. "Dos caras de los derechos en el gobierno de Mujica”. In: Busquets, José Miguel (Coord.). Políticas en tiempos del Mujica III. Montevideo: Estuario Editora, 2013.

GuTIÉRrez, Ramón. “Una nueva generación de militantes: apuntes sobre no a la baja”. ZUR Pueblo de Voces. 2014. Disponível em: <zur.org.uy>. Acesso em: 17/04/2015.

Johnson, Niki; Gómez, Alejandra López; Schenck, Marcela. "La sociedad civil ante la despenalización del aborto: Opinión pública y movimientos sociales”. In: JoHnson, Niki et al. (Des) penalización del aborto en Uruguay: prácticas, actores y discursos. Abordaje interdisciplinario sobre una realidad compleja. Montevideo: UdELAR-CsIC, 2011. p. 238-263.

LóPEZ LeYva, Miguel Armando. "Los movimientos sociales y su influencia en el ciclo de las políticas públicas”. Región y Sociedad, Año XXIV, nº 55, p. 159-198, 2012.

Machado, Jorge Alberto. "Movimientos sociales y activismo en red”. In: Congreso OnLIne del Observatorio para la Cibersociedad, II. Papers... Barcelona, 2004.

MARTi I PUig, Salvador. “Los movimientos sociales”, Salamanca, Universidad de Salamanca. Disponível em: <usal.es/ dpublico/areacp/materiales/Losmovimientossociales.pdf > . Acesso em: 17/04/2015. 
Rodríguez Arechavaleta, Carlos Manuel. “De la estructura de oportunidades a la identidad colectiva. Apuntes teóricos sobre el poder, la acción colectiva y los movimientos sociales”. Espacios Públicos, v. 13, n. 27, p. 187-215, 2010.

SEmpol, Diego. "Familias en debate: unión concubinaria y formas de integración política de la diferencia”. In: Gioscia, Laura (Coord.). ¿Más Allá de la tolerancia? Ciudadanía y diversidad en el Uruguay Contemporáneo. Montevideo: Ediciones Trilce, 2014.

Zibechi, Raúl. La mirada horizontal. Movimientos sociales y emancipación. Quito: Ediciones Abya-Ayala, 2000. 